\title{
Potential tenfold drug overdoses on a neonatal unit
}

\author{
K Chappell, C Newman
}

Arch Dis Child Fetal Neonatal Ed 2004;89:F483-F484. doi: 10.1136/adc.2003.041608

Nearly one third of intravenous drug prescriptions on a neonatal unit were for doses less than one tenth of a single drug vial. Tenfold drug errors in prescribing are well documented and with the continued use of vials containing adult size doses, great potential exists for serious administration errors.

$\mathrm{N}$ eonates are particularly vulnerable to the effects of medication errors, and it has been previously reported that $8 \%$ of doses calculated by neonatal intensive care staff during a test were incorrect by a factor of $10 .{ }^{1}$ When medication errors were studied in a paediatric teaching hospital, 195 medication errors were reported over a five year period, $15(8 \%)$ of which were due to a 10 -fold error. ${ }^{2}$ There have been several individual reports of harmful or fatal errors resulting from 10 -fold or 100 -fold errors-that is, decimal point errors-in prescribing, preparation, or administration. ${ }^{3}{ }^{4}$

This potential for serious error is exacerbated by the high strength of intravenous vials, manufactured to provide adult size doses. Conroy et al ${ }^{5}$ reported that about 55\% of prescriptions in neonatal intensive care use drugs "off label" and that $10 \%$ use unlicensed drugs. Hence the lack of licensed drug products available in appropriate vial sizes for this group of patients further contributes to the chances of administering a large overdose.

This study aimed to determine the proportion of prescribed intravenous drug doses where it was possible to administer a 10 -fold or 100-fold overdose from the vials routinely used on the neonatal unit.

\section{METHOD}

Over a six week period in 2001, all intravenous drugs prescribed on the neonatal unit at the Queen's Medical Centre, Nottingham were recorded. Information collected included patient details, drug, dose, frequency, and number of doses given. A prescription was defined as either a single dose or a course of treatment. Standard intravenous replacement fluids were not recorded. The doses prescribed for each drug were compared with the lowest available strength vial of that drug.

\section{RESULTS}

A total of 336 intravenous prescriptions were recorded, and 1348 intravenous drug doses given. Of these, 104 (31\%) prescriptions were for doses less than one tenth of the contents of a vial, thus creating the potential to give a 10 -fold overdose from a single vial. This equated to 333 intravenous doses (25\% of doses administered). Also, 16 (4.8\%) prescriptions were for doses less than one hundredth of a vial, with the potential to administer a 100 -fold overdose from a single vial. This equated to 32 intravenous doses $(2.4 \%$ of doses administered).
Tables 1 and 2 list the drugs most often administered at doses less than one tenth or one hundredth of a vial respectively.

\section{DISCUSSION}

With $31 \%$ of intravenous drugs prescribed at a dose less than one tenth of a vial and the known high incidence of 10-fold prescribing errors in neonatal patients, there is great potential for serious medication errors. Many of the drugs highlighted in tables 1 and 2 would cause considerable morbidity or mortality in 10-fold or 100-fold overdose. Deaths from opiate overdoses have been reported, ${ }^{4}$ as has a case of acute renal failure following the administration of $50 \mathrm{mg}$ gentamicin instead of $5 \mathrm{mg}^{3}$

Even though it is not commonplace for pharmacy departments in the United Kingdom to supply all intravenous doses in a ready to use form, these results highlight the benefits of such a centralised intravenous additives service. In the absence of such a service, the availability of drugs in lower strength vials would help to minimise the risk of medication error from the use of inappropriate dose forms.

\section{CONCLUSION}

The potential for administering 10-fold or 100-fold intravenous drug overdoses to neonates from a single vial is great.

\begin{tabular}{|c|c|c|}
\hline Drug & $\begin{array}{l}\text { No of doses } \\
\text { administered } \\
\text { equivalent to less } \\
\text { than one tenth of } \\
\text { a vial }\end{array}$ & $\begin{array}{l}\% \text { of doses of } \\
\text { that drug }\end{array}$ \\
\hline Furosemide & 60 & 83 \\
\hline Cefotaxime & 51 & 52 \\
\hline Benzylpenicillin & 30 & 14 \\
\hline Diamorphine & 27 & 23 \\
\hline Ranitidine & 24 & 100 \\
\hline Gentamicin & 13 & 8 \\
\hline Dexamethasone & 13 & 76 \\
\hline Indometacin & 11 & 69 \\
\hline Insulin & 11 & 100 \\
\hline Atracurium & 9 & 41 \\
\hline
\end{tabular}

Table 2 Intravenous drugs administered at doses less than one hundredth of a vial

\begin{tabular}{lll}
\hline Drug & $\begin{array}{l}\text { No of doses administered } \\
\text { equivalent to less than one } \\
\text { hundredth of a vial }\end{array}$ & $\begin{array}{l}\% \text { of doses of that } \\
\text { drug }\end{array}$ \\
\hline Diamorphine & 14 & 12 \\
Insulin & 10 & 91 \\
Potassium canrenoate & 6 & 100 \\
Midazolam & 2 & 18 \\
\hline
\end{tabular}


This risk will remain as long as drug vials are manufactured only in adult size doses. National or European initiatives are urgently needed to ensure the manufacture of neonatal targeted products to reduce the risks associated with intravenous drug administration.

\section{Authors' affiliations}

K Chappell, C Newman, Pharmacy Department, QMC University Hospital, Nottingham NG7 2UH, UK

Correspondence to: Mrs K Chappell, Pharmacy Department, QMC University Hospital, Derby Road, Nottingham NG7 2UH;

karen.chappell@mail.qmcuh-tr.trent.nhs.uk
Accepted 24 November 2003

\section{REFERENCES}

1 Perlstein PH, Callison C, White $M$, et al. Errors in drug computations during newborn intensive care. Am J Dis Child 1979;133:376-9.

2 Ross LM, Wallace J, Paton JY. Medication errors in a paediatric teaching hospital in the UK: five years operational experience. Arch Dis Child 2000;83:492-7.

3 Koren G, Barzilay Z, Greenwald M. Tenfold errors in administration of drug doses: a neglected iatrogenic disease in paediatrics. Paediatrics 1986:77:848-9.

4 Anon. Zeroing in on medication errors. Lancet 1997:349:369.

5 Conroy S, Mclntyre J, Choonara I. Unlicensed and off label drug use in neonates. Arch Dis Child Fetal Neonatal Ed 1999;80:F142-5.

\section{Call for Book Reviewers}

Book reviews are a popular feature of $A D C$, and many readers use them to decide how best to spend scarce library funds. We need to recruit a team of willing reviewers, both generalists and specialists, who are prepared to read and review new books (and CD-ROMs, etc) within a three-month deadline: could you help? You will have the option to decline if you can't manage a review in time.

Unfortunately $A D C$ cannot pay reviewers, but you will be able to keep the book for yourself or your department. Trainees are particularly welcome to apply.

For logistical reasons reviewers should be based in the UK or Republic of Ireland and internet access is essential.

Please contact archdischild@bmjgroup.com with brief details of special interests and reviewing experience, if any (include BOOK REVIEWS in the subject field). 